\title{
Morphology of left ventricular outflow tract structures in patients with subaortic stenosis and a ventricular septal defect
}

\author{
D Kitchiner, M Jackson, N Malaiya, K Walsh, I Peart, R Arnold, A Smith
}

\begin{abstract}
Objective-To compare the incidence and prognosis of subaortic stenosis associated with a ventricular septal defect and to define the morphological basis of
\end{abstract} subaortic stenosis.

Design-Presentation and follow up data on 202 patients with subaortic stenosis seen at the Royal Liverpool Children's Hospital between 1 January 1960 and 31 December 1991 were reviewed. Survivors were traced to assess their current clinical state. Necropsy specimens of 291 patients with lesions associated with subaortic stenosis were also examined.

Results-In the clinical study; 65 (32.1\%) of the 202 patients with subaortic stenosis had a ventricular septal defect (excluding an atrioventricular septal defect). 32 of these patients had a short segment (fibromuscular) subaortic stenosis. 33 had subaortic stenosis produced by deviation of muscular components of the outflow tracts. In 17 patients $(51.5 \%)$ this was caused by posterior deviation or extension of structures into the left ventricular outflow tract, resulting in obstruction above the ventricular septal defect. In the other 16 patients $(48 \cdot 5 \%)$ there was overriding of the aorta with concordant ventriculoarterial connections, (without compromise to right ventricular outflow) producing subaortic stenosis below the ventricular septal defect. Additional fibrous obstruction occurred in $39 \%$ of the patients with deviated structures. The age at presentation was lower $(P<0.01)$ in patients with deviated structures (median (range) 0.4 (0 to 9.2) months) than in those with short segment obstruction (median (range) $4 \cdot 2$ (0 to 84.9) months). The incidence of aortic arch obstruction was higher $(P<0.002)$ in patients with deviated structures than in those with short segment obstruction (38\%). In the morphological study 35 pathological specimens showed obstructive muscular structures in the left ventricular outflow tract either above or below the ventricular septal defect. 16 had either posterior deviation of the outlet septum or extension of the right ventriculoinfundibular fold, or both of these together into the left ventricle. 19 had anterior deviation of the outlet septum into the right ventricle with overriding of the aorta (without compromise to right ventricular outflow). The earliest age at which additional fibrous obstruction was seen was 9 months. The aortic valve circumference was small in $18 \%$ of specimens.

Follow up-The median (range) duration of follow up in survivors from the clinical study was $6.6(1$ to $25 \cdot 7)$ years. 16 patients with deviated musculature (49\%) and 16 with short segment fibromuscular stenosis $(50 \%)$ underwent operation for subaortic stenosis. Patients with deviated structures were younger at operation than those with short segment stenosis $(P<0.005)$. Patients with posterior deviation or extension of structures into the left ventricular outflow tract underwent operation for subaortic stenosis more frequently $(P<0.05)$ than those with anterior deviation of the outlet septum and aortic override. The ventricular septal defect required surgical closure more frequently $(P<0.005)$ in patients with deviation $(93.9 \%)$ than in those with short segment obstruction (21.9\%). There was no significant difference in the mortality between patients with deviation (27\%) and those with short segment obstruction $(12 \%)$.

Conclusions $-32 \%$ of patients in the clinical study with subaortic stenosis had a ventricular septal defect. Only $51 \%$ of these had obstructive and deviated muscular structures in the left ventricular outflow tract. These patients had a significantly higher incidence of aortic arch obstruction and required surgery for subaortic stenosis at a younger age than those with short segment obstruction. The ventricular septal defect also required surgical closure more frequently in those patients with deviation. The morphological study defined the two sites of obstruction. The presence or absence and type of deviation should be clearly defined in all patients with a ventricular septal defect, because of the potential for the development of subaortic stenosis.

(Br Heart f 1994;72:251-260)

In patients with a ventricular septal defect, subaortic stenosis may be caused by either deviation of components of the outflow tracts, ${ }^{1-3}$ or by a short segment obstruction ${ }^{4}$ (also called a fibrous, fibromuscular, or membranous obstruction). ${ }^{56}$ Reports of patients 

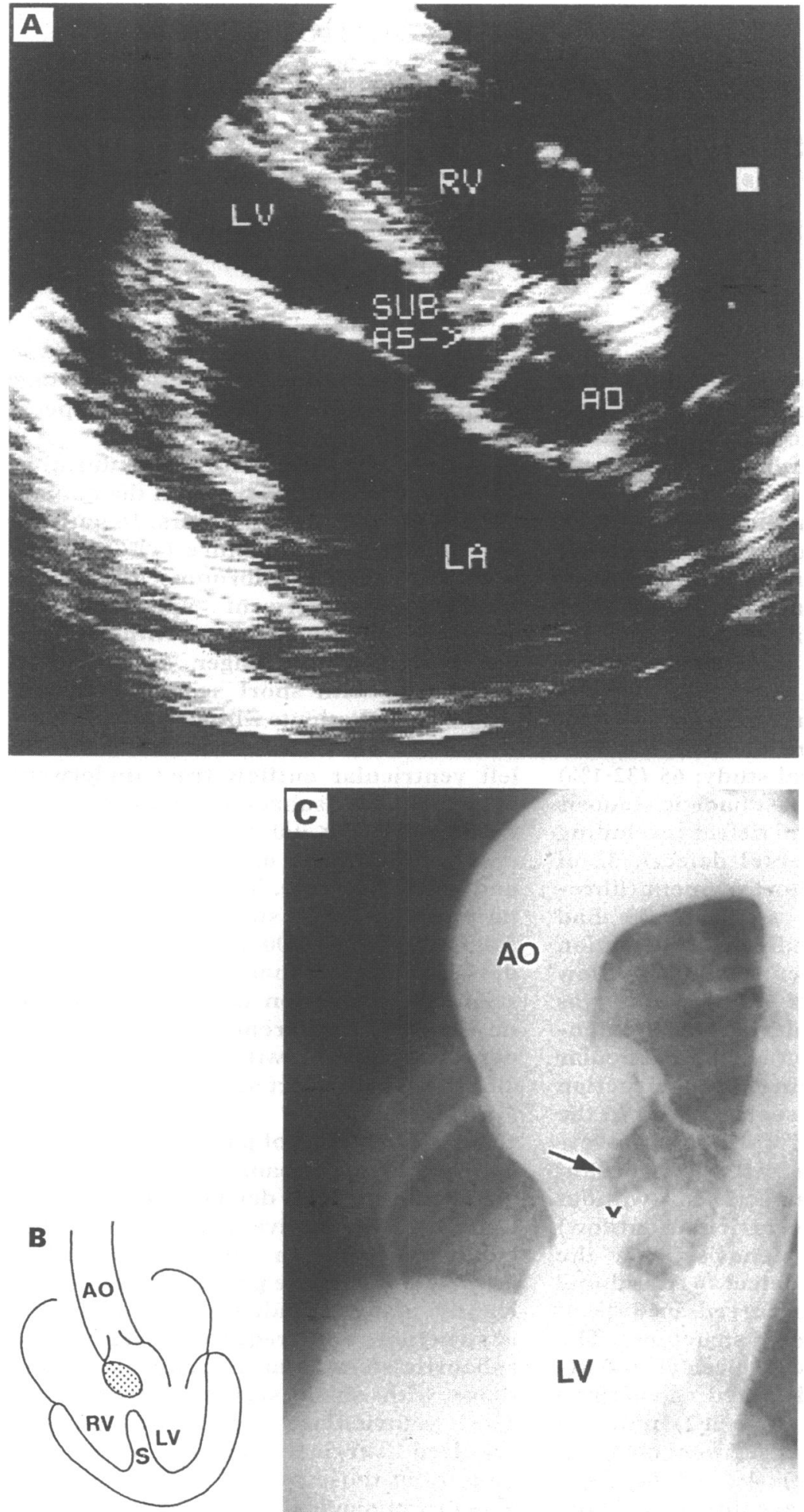

Figure 1 (A) Cross sectional echocardiogram in the long axis parasternal view showing posterior deviation of the outlet septum into the left ventricular outflow tract, resulting in subaortic obstruction above the ventricular septal defect. (B) Diagram of posterior deviation of the outlet septum into the left ventricle, showing the mechanism of production of obstruction above the ventricular septal defect. (C) Left ventricular angiogram showing posterior deviation of the outlet septum into the left ventricular outflow tract (arrow), which causes obstruction above the ventricular septal defect. $A O$, aorta; $L A$, left atrium $L V$, left ventricle; $R V$, right ventricle; $S$, interventricular septum; $S U B A S$, subaortic stenosis; $V$, ventricular septal defect.

with a ventricular septal defect and subaortic stenosis $^{7-9}$ seldom mention the presence of deviated muscular structures. ${ }^{31011}$

The aims of this study were to determine the incidence and prognosis of patients with subaortic stenosis and a ventricular septal defect, with and without deviation of the com- ponents of the outflow tracts. The structures involved in the different types of deviation are defined.

Overriding of the arterial valve (biventricular origin) describes the situation in which the valve does not originate wholly from its appropriate ventricle (concordant ventriculoarterial connection) but is connected partially to the other ventricle across a ventricular septal defect. The ventriculoarterial connections can still be concordant in the presence of an overriding valve as long as that valve is predominantly connected to its appropriate ventricle. The right ventriculoinfundibular fold is the muscle bar that separates the tricuspid valve from the arterial valve of the right ventricle. It is produced by the infolding of the heart wall and is part of the freestanding pulmonary infundibulum. The outlet septum is the portion of muscle that separates the aortic from the pulmonary outlet. This structure is more easily identifiable in the abnormal than in the normal heart. Most of the subpulmonary infundibulum is free standing and in the normal heart only a small portion of the septal surface is the outlet septum. Deviation is defined as the displacement of the superior border of the ventricular septal defect (formed by the outlet septum, or the right ventriculoinfundibular fold, or both) in relation to the inferior border of the ventricular septal defect (formed by the trabecular septum). Posterior deviation occurs when the outlet septum or right ventriculoinfundibular fold is displaced or extends posteriorly into the left ventricular outflow tract. Anterior deviation occurs when the outlet septum is displaced anteriorly into the right ventricle and is associated with aortic override without compromise to the right ventricular outflow tract.

\section{Patients and methods}

\section{CLINICAL STUDY}

We reviewed the echocardiographic, angiographic, operative, and morphological features of all 202 patients with subaortic stenosis seen at the Royal Liverpool Children's Hospital between 1 January 1960 and 31 December 1991. The diagnosis of deviation was made by cross sectional echocardiography in the long axis view ${ }^{11}$ or by left ventricular angiography in the left anterior oblique view. ${ }^{10}$ Patients with a hypoplastic left ventricle, mitral or aortic valve atresia, discordant atrioventricular or ventriculoarterial connections, or an atrioventricular septal defect were excluded. Patients were traced to assess their current clinical status, and cross sectional and continuous wave Doppler (1.9 or $2.0 \mathrm{Mhz}$ ) echocardiography was carried out with a Hewlett-Packard Sonos 500 ultrasound system.

\section{MORPHOLOGICAL STUDY}

We also examined the necropsy specimens of 291 patients with aortic valve or arch obstruction, mitral valve abnormalities, or ventricular septal defect to ensure that all those with deviation were included. These specimens are from the collection of pathological material in 

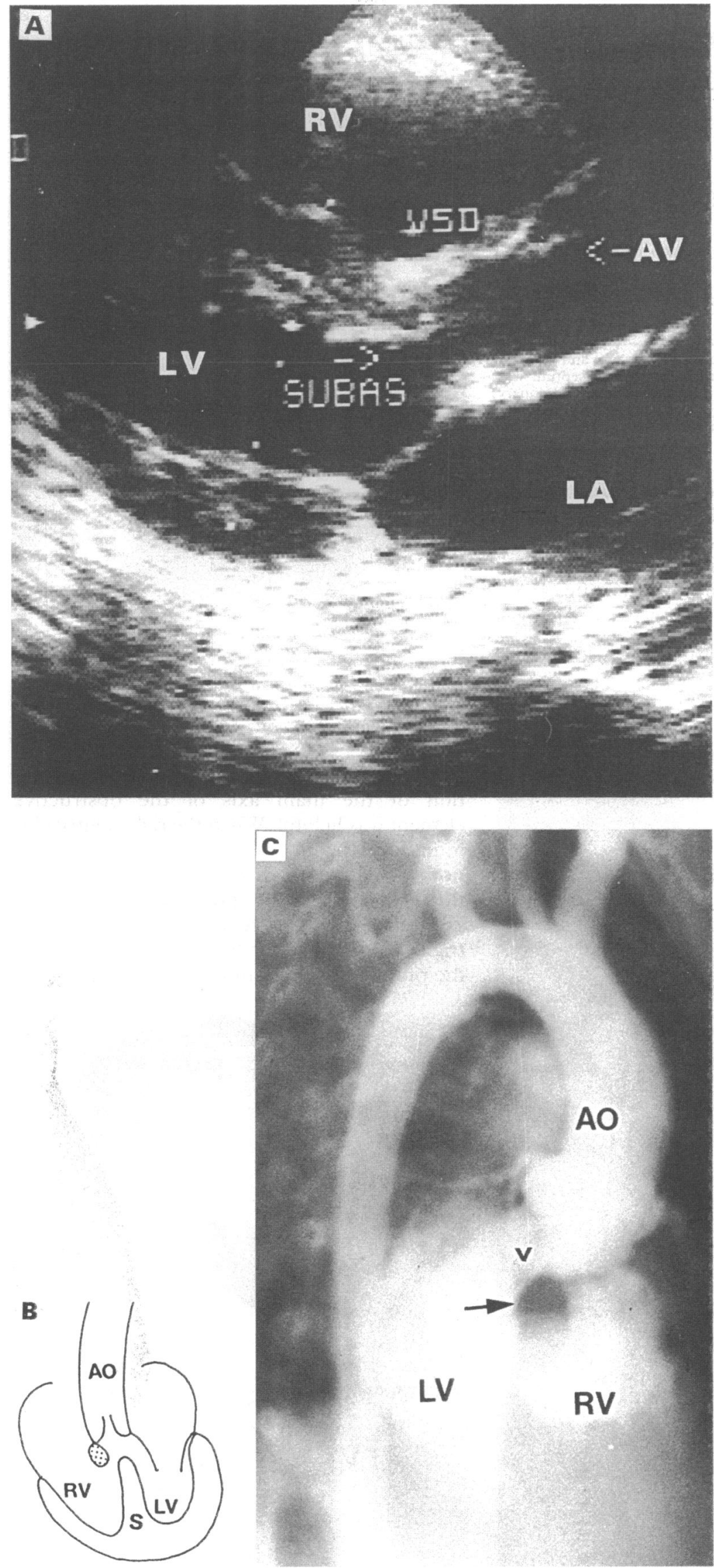

Figure 2 (A) Cross sectional echocardiogram in the long axis parasternal view showing anterior deviation of the outlet septum into the right ventricle and obstruction below the ventricular septal defect. The ventricular septal defect has been closed surgically. (B) Diagram of anterior deviation of the outlet septum into the right ventricle, showing the mechanism of production of obstruction below the ventricular septal defect. (C) Left ventricular angiogram showing anterior deviation of the outlet septum into the right ventricle (without right ventricular outflow obstruction), producing aortic override and potential subaortic obstruction below the ventricular septal defect (arrotw). Abbreviations as for fig 1 . the Institute of Child Health, University of Liverpool.

\section{STATISTICAL ANALYSIS}

Statistical significance was tested with the Yates corrected Fisher-Irwin (Fisher's exact) test. ${ }^{12}$ Results were considered significant at $P \leqslant 0 \cdot 05$. Continuously distributed data were explored with the Mann-Whitney test ${ }^{13}$ and presented as medians with range. Actuarial analysis of freedom from operation for subaortic stenosis was conducted with the product limit method of Kaplan-Meier. ${ }^{14}$

\section{Results}

CLINICAL STUDY

Sixty five of the 202 patients (32\%) with subaortic stenosis had a ventricular septal defect.

PATIENTS WITH SHORT SEGMENT SUBAORTIC STENOSIS WITHOUT DEVIATION

Thirty two patients ( 19 males and 13 females) had a short segment (also called fibrous, fibromuscular, or membranous) subaortic stenosis without deviation of the components of the outflow tracts. In eight of these patients the obstruction occurred above the ventricular septal defect, and in 24 it was below the ventricular septal defect. The median (range) age at presentation was $4 \cdot 2$ (0 to 84.9$)$ months.

\section{Patients with deviation}

Thirty three patients (19 males, 14 females) had subaortic stenosis associated with deviation of the components of the outflow tracts. Seventeen patients had posterior deviation. This caused obstruction above the ventricular septal defect (fig 1). Two of these patients also had overriding of the pulmonary trunk. In 16 patients there was anterior deviation, producing subaortic stenosis below the ventricular septal defect (fig 2). Additional fibrous obstruction was found in 13 patients $(39.4 \%)$. In six patients this was associated with posterior deviation (fig 3), and in seven with anterior deviation. The median (range) age at presentation was 0.4 (0 to $9 \cdot 2)$ months, and this was significantly younger $(P<0.01)$ than those with short segment obstruction.

\section{MORPHOLOGICAL STUDY}

Thirty specimens showed deviation. These patients died early in life, usually as a result of aortic arch obstruction. Subaortic stenosis had not been shown clinically, but would undoubtedly have occurred with time. Another five specimens from patients in the clinical study group who subsequently died, were also available for study. Examination of the pathological specimens allowed further definition of both the types of deviation and the structures involved (table 1).

Sixteen specimens showed obstruction above the ventricular septal defect, separating it from the aortic valve. In four specimens this was caused by posterior deviation of the outlet septum, and in six due to extension of the right ventriculoinfundibular fold into the left 
Table 1 Site of the ventricular septal defect and orientation of intracardiac structures related to the great vessels in the outlet of the heart, in the 35 necropsy specimens in the morphological study

\begin{tabular}{lll}
\hline & $\begin{array}{l}\text { Outlet septum, } \\
R V I F, \text { or both } \\
\text { to LV } \\
(n=16)\end{array}$ & $\begin{array}{l}\text { Outlet septum } \\
\text { to } R V \\
(n=19)\end{array}$ \\
$\begin{array}{lll}\text { Intracardiac } \\
\text { arrangements }\end{array}$ & $\begin{array}{l}\text { Obstruction } \\
\text { above VSD }\end{array}$ & $\begin{array}{l}\text { Obstruction } \\
\text { below VSD }\end{array}$ \\
\hline $\begin{array}{l}\text { Inlet VSD } \\
\text { Outlet VSD } \\
\text { Trabecular VSD }\end{array}$ & 2 & 6 \\
$\begin{array}{l}\text { Biventricular origin of Ao } \\
\text { Biventricular origin of PT }\end{array}$ & 9 & 5 \\
No override of Ao or PT & 4 & 8 \\
\hline
\end{tabular}

*In three specimens an outlet septum was absent, and in one it was hypoplastic. +In three specimens the outlet septum was was hypoplastic. +In three specimens the outlet septum was
hypoplastic. Ao, aorta; LV, left ventricle; PT, pulmonary hypoplastic. Ao, aorta; LV, left ventricle; PT, pulmonary
trunk; RV, right ventricle; RVIF, right ventriculoinfundibular trunk; RV, right ventricle; RVIF, right
fold; VSD, ventricular septal defect.

ventricular outflow tract. In a further six, obstruction was caused by both posterior deviation of the outlet septum and extension of the right ventriculoinfundibular fold into the left ventricular outflow tract (fig 4(A). The distinction between these two structures

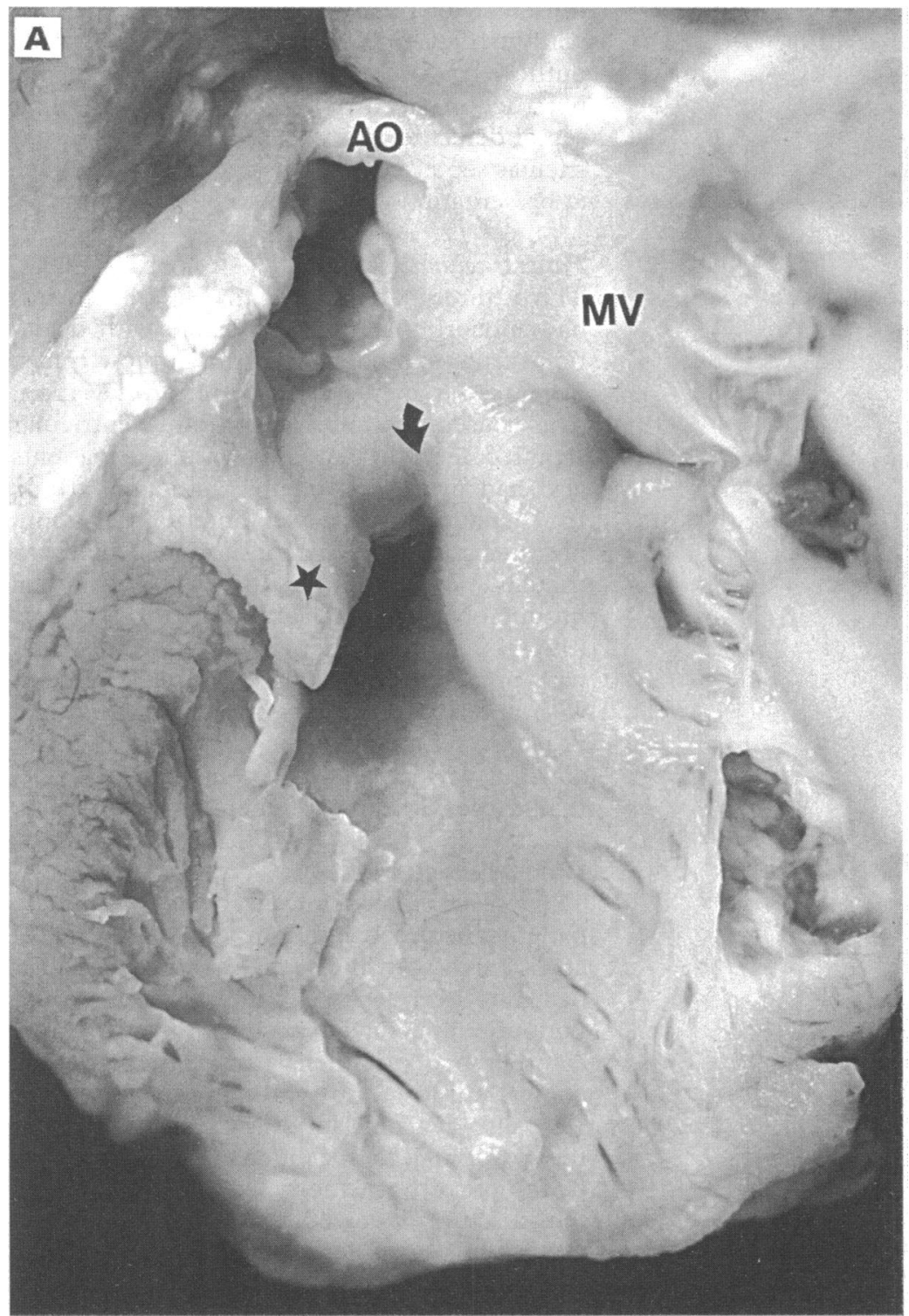

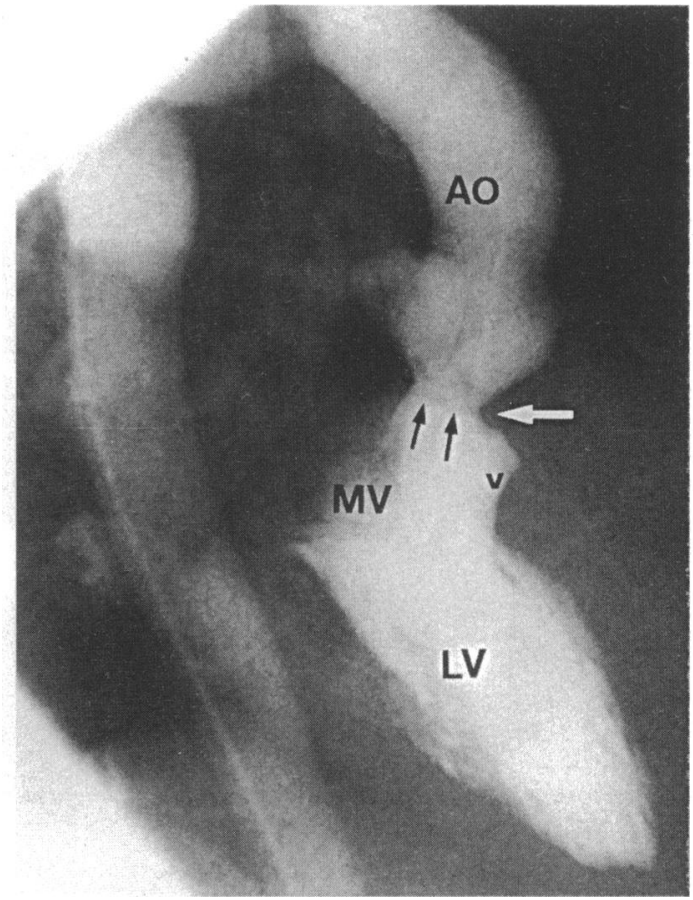

Figure 3 Left ventricular angiogram in a patient with posterior deviation of the outlet septum, showing muscular subaortic stenosis (white arrow) above the site of a previous ventricular septal defect. There is additional fibrous obstruction (black arrows). $M V$, mitral valve; other abbreviations as for fig 1 .

was not always easy to discern, but the angulation of the main axis of the obstructive element was helpful. When the right ventriculoinfundibular fold was involved, the obstruction ran closer to the mitral valve. In 12 of these specimens the pulmonary trunk was not related to the ventricular septal defect (fig $4(B)$ ) but in four there was overriding of the pulmonary trunk into the left ventricle. In

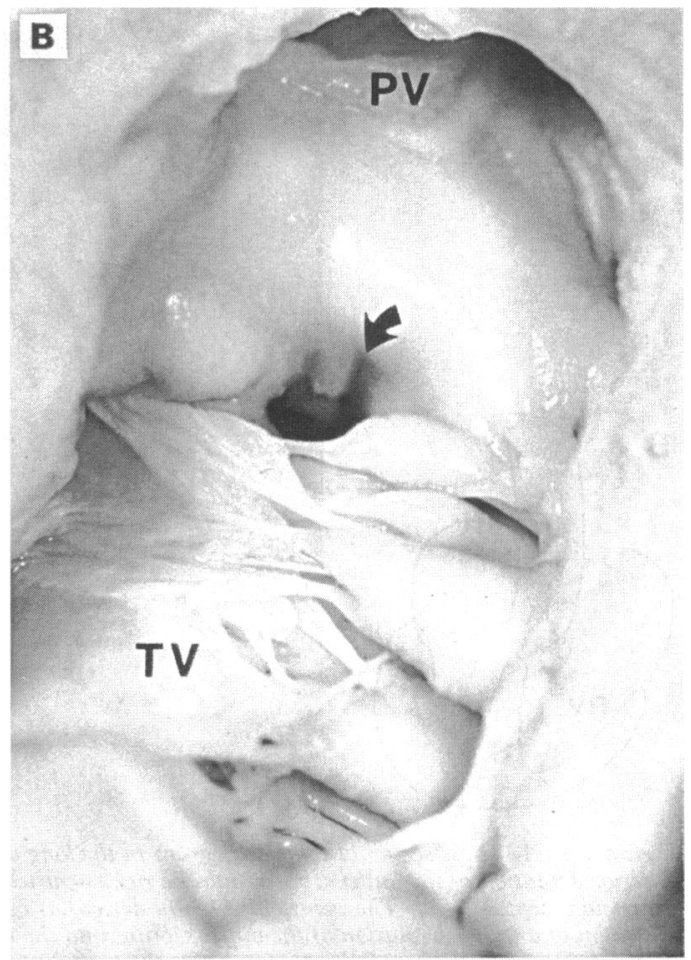

Figure $4(A)$ Necropsy specimen showing the left ventricle of a heart with obstruction above the ventricular septal defect caused by posterior deviation of the outlet septum (asterisk) together with extension of the right ventricular infundibular fold (arrow). (B) Necropsy specimen of the right ventricle of the specimen shown in $(A)$ showing that the pulmonary trunk was not related to the ventricular septal defect (arrow). PV, pulmonary valve; TV tricuspid valve; other abbreviations as for fig 3 . 

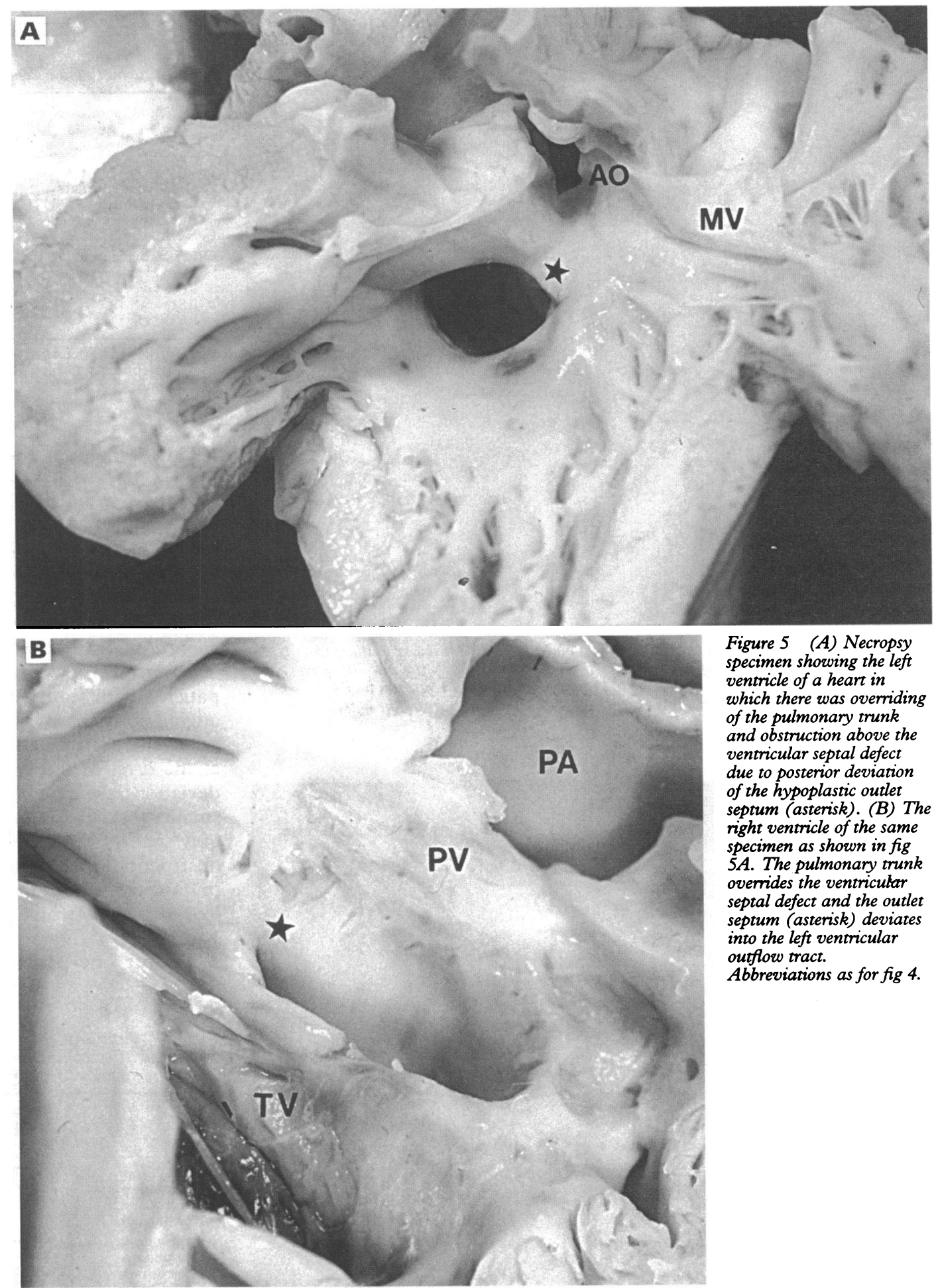

Figure 5 (A) Necropsy specimen showing the left ventricle of a heart in which there was overriding of the pulmonary trunk and obstruction above the ventricular septal defect due to posterior deviation of the hypoplastic outlet septum (asterisk). (B) The right ventricle of the same specimen as shown in fig $5 A$. The pulmonary trunk overrides the ventricular septal defect and the outlet septum (asterisk) deviates into the left ventricular outflow tract.

Abbreviations as for fig 4.

three of these the outlet septum was absent and the pulmonary and aortic valves were in fibrous continuity. The obstruction was produced by the right ventriculoinfundibular fold only, which extended into the left ventricular outflow tract. In the other specimen the outlet septum was hypoplastic, but extended as an enlarged anterolateral muscle bundle into the left ventricular outflow tract (fig 5).

In 19 specimens there was anterior deviation. The outlet septum deviated anteriorly over the right ventricular cavity, overriding the aorta without compromise to the right ventricular outflow tract. This produced the potential for left ventricular outflow tract obstruction below the ventricular septal defect (fig 6). In all specimens the outlet septum was present, but it was hypoplastic in three cases.

None of the specimens from patients who died early in life showed additional fibrous obstruction. Specimens from two patients (one with posterior and one with anterior deviation had additional fibrous obstruction in the left ventricular outflow tract (fig 7). The age at death in these patients was 9 and 11 months. 


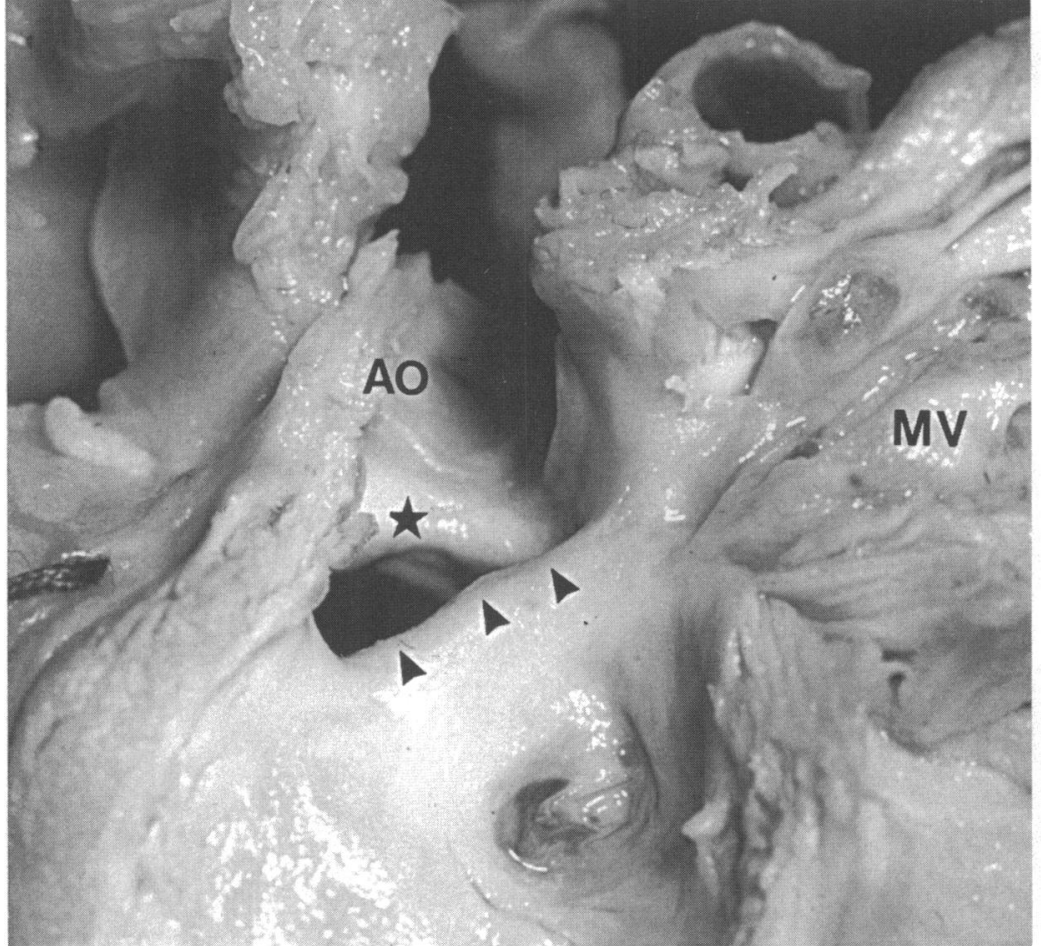

Figure 6 Necropsy specimen showing obstruction in the left ventricular outflow tract below the ventricular septal defect (arrows). The outlet septum deviates into the right ventricle producing overriding of the aorta. A portion of the inlet septum is almost transparent where it apposes the dysplastic leaflets of the mitral valve. The reason for this is not clear. Abbreviations as for fig 3.

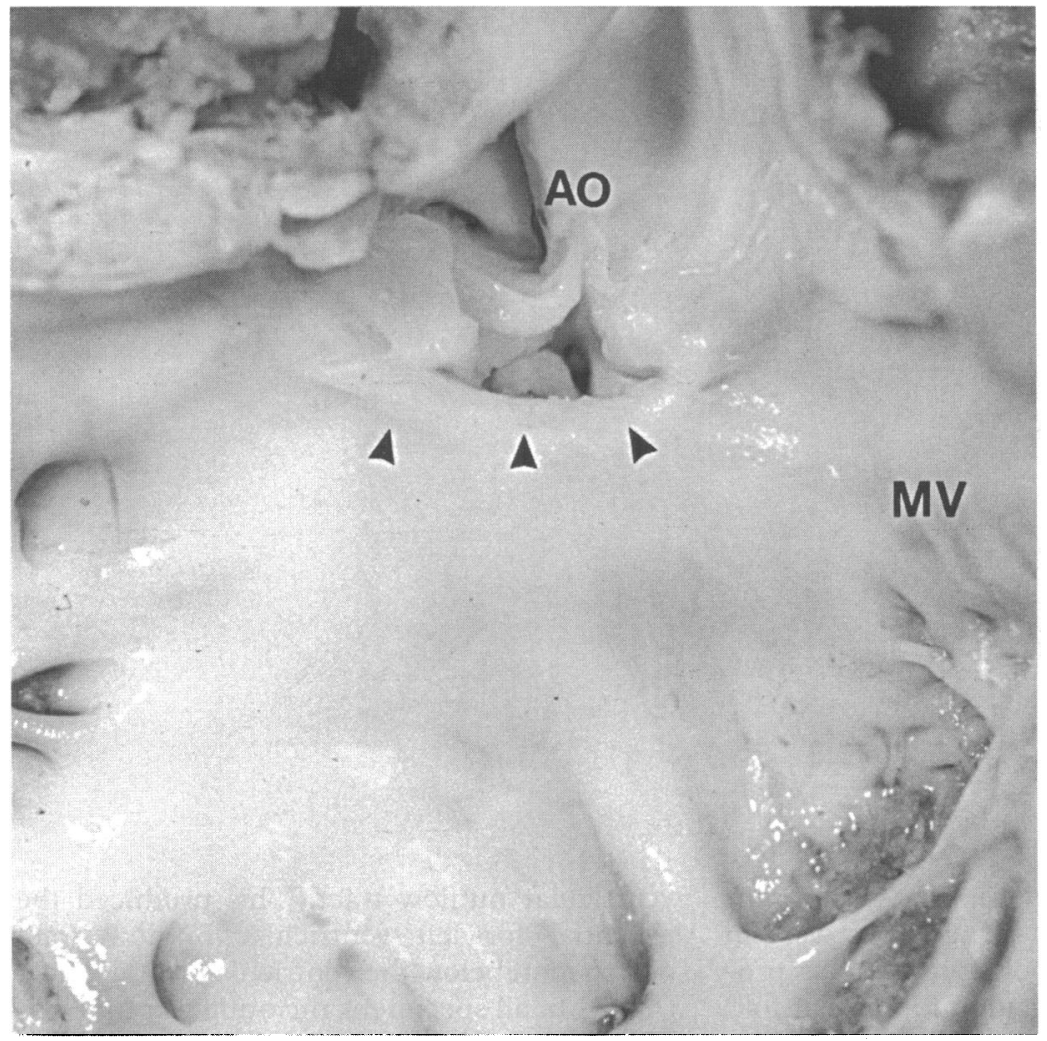

Figure 7 Necropsy specimen of the left ventricle showing obstruction below the ventricular septal defect produced by an accretion of fibrous material (arrows) on the apical margin. The aorta has a biventricular origin. The pearly appearance of the endocardium shows that endocardial fibroelastosis is present in the left ventricle. Abbreviations as for fig 3.

\section{ASSOCIATED CARDIAC LESIONS}

Table 2 shows the distribution of other cardiac lesions. The incidence of aortic arch obstruction was significantly higher $(P<0.002)$ in patients with deviation
Table 2 Other cardiac lesions in 33 patients with subaortic stenosis caused by deviation of structures in the outflow tracts, and 32 patients with short segment (fibromuscular) subaortic stenosis and a ventricular septal defect

\begin{tabular}{lll}
\hline & $\begin{array}{l}\text { Patients with deviation } \\
\text { of outflow } \\
\text { tract structures }\end{array}$ & $\begin{array}{l}\text { Patients with } \\
\text { short segment } \\
\text { obstruction }\end{array}$ \\
\hline Aortic arch abnormality: & & \\
Coarctation & 10 & 12 \\
Interruption & 15 & 0 \\
$\quad$ Normal arch & 8 & 20 \\
Other cardiac lesions: & & \\
Mitral valve disease & 3 & 2 \\
PDA & 25 & 10 \\
ASD & 0 & 1 \\
RVOTO & 0 & 3 \\
\hline
\end{tabular}

ASD, atrial septal defect; LVOT, left ventricular outflow tract, PDA, patent arterial duct; RVOTO, right ventricular outflow obstruction.

$(75 \cdot 8 \%)$, than in those with short segment obstruction $(37 \cdot 5 \%)$. There was no difference in the type or distribution of aortic arch obstruction between the two types of deviation (table 3), in either the clinical or morphological study groups.

\section{AORTIC ROOT AND VALVE}

Clinical study

Twenty seven patients with deviation and 19 patients with short segment obstruction, had angiography that was suitable to measure the relative sizes of the aorta and pulmonary trunk at the level of the valve. In all patients with deviation the diameter of the aorta was smaller than the pulmonary trunk (table 4). In only six of the 19 patients with short segment obstruction the aorta was smaller than the pulmonary trunk. The median (range) aortic to pulmonary trunk ratio was $1.05(0.8$ to 1.42).

Twenty one patients $(63.6 \%)$ with devia-

Table 3 Aortic arch obstruction in 33 patients (clinical study) and 35 specimens (morphological study) with deviation of outflow tract structures

\begin{tabular}{cll}
\hline & $\begin{array}{l}\text { Posterior deviation } \\
\text { of structures } \\
\text { into LVOT }\end{array}$ & $\begin{array}{l}\text { Anterior deviation } \\
\text { of OS with } \\
\text { aortic override }\end{array}$ \\
\hline Clinical group: & $\mathrm{n}=17$ & $\mathrm{n}=16$ \\
Coarctation & 7 & 3 \\
Interruption & 7 & 8 \\
Normal arch & 3 & 5 \\
Necropsy group: & $\mathrm{n}=16$ & $\mathrm{n}=19$ \\
Coarctation & 11 & 9 \\
Interruption & 2 & 6 \\
Normal arch & 3 & 4 \\
\hline
\end{tabular}

LVOT, left ventricular outflow tract; OS, outlet septum.

Table 4 Relative size of the aorta and pulmonary trunk in 27 patients in the clinical study in whom the diameter was measured on angiogram, and in 32 specimens in the morphological study where it was measured as a circumference

\begin{tabular}{lll}
\hline & $\begin{array}{l}\text { Posterior deviation } \\
\text { of structures } \\
\text { into LVOT }\end{array}$ & $\begin{array}{l}\text { Anterior deviation } \\
\text { of OS with } \\
\text { aortic override }\end{array}$ \\
\hline $\begin{array}{l}\text { Clinical group: } \\
\text { Median (range) }\end{array}$ & $0.65(0.41-0.87)$ & $0.76(0.62-0.93)$ \\
$\begin{array}{l}\text { Ao/PT ratio } \\
\text { Necropsy group: } \\
\text { Median (range) }\end{array}$ & $0.66(0.33-0.86)$ & $0.69(0.45-0.9)$ \\
\begin{tabular}{c} 
Ao/PT ratio \\
\hline
\end{tabular}
\end{tabular}

Ao, aorta; LVOT, left ventricular outflow tract; OS, outlet septum; PT, pulmonary trunk. 
tion had a trileaflet and six had a bileaflet valve without stenosis. In six patients there was additional aortic valve stenosis. In patients with short segment obstruction, 25 (78.1\%) had a trileaflet aortic valve, three had a bileaflet valve without stenosis, and four had additional aortic valve stenosis.

\section{Morphological study}

The circumference of the aorta and pulmonary trunk was measured in $\mathbf{3 2}$ of the 35 specimens. The aortic circumference was within normal limits in $26,,^{15}$ but in six specimens $(18 \%)$ it was below the lower limit of normal. Three of these specimens had posterior, and three had anterior deviation. The circumference of the pulmonary trunk was larger than normal in 19 specimens $(59 \cdot 4 \%){ }^{15}$ Table 4 shows the relative size of the aorta and pulmonary trunk in the pathological specimens. The aortic valve was trileaflet in 22 patients $(62.9 \%)$ and bileaflet in 13 .

\section{FOLLOW UP}

Clinical study

All survivors were followed up for a median (range) duration of $6.6(1.1$ to $25 \cdot 7)$ years, giving 454 patient-years of follow up. No patient was lost to follow up.

\section{SURGERY}

Clinical study

Sixteen of the 33 patients with deviation (48.5\%) underwent 18 operations for subaortic stenosis. In 11 of these patients the indication for the first operation was closure of the ventricular septal defect, and tissue was resected from the left ventricular outflow tract through the ventricular septal defect during the same operation. The median (range) age at operation was 9 (2 to 20) months. In five patients (median (range) age 33 (19 to 109) months) the indication for operation was subaortic stenosis, after previous closure of a ventricular septal defect. Four of these patients with posterior deviation and obstruction above the

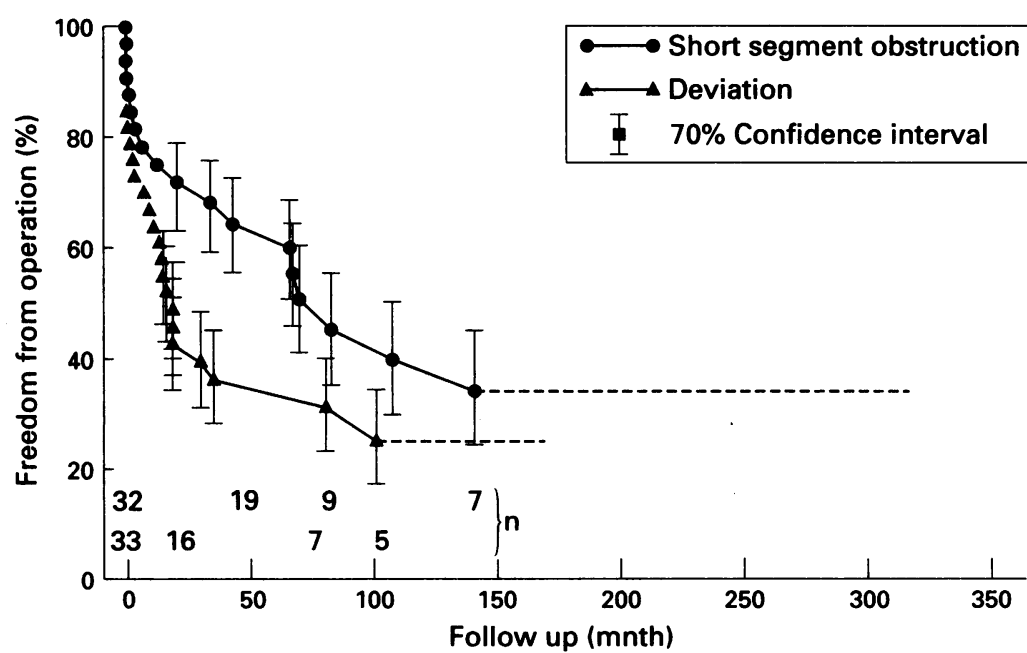

Figure 8 Actuarial freedom from operation for subaortic stenosis in patients with a ventricular septal defect, with and without deviation of structures in the left ventricular outflow tract. Broken lines beyond the last event show the continued follow up of live patients free from operation. ventricular septal defect, had resection of subaortic stenosis through the aortic valve. One patient with anterior deviation and obstruction below the site of the previous ventricular septal defect had a modified Konno procedure. The indication for reoperation in two patients was subaortic stenosis, and resection was carried out through the aortic valve. Twenty nine patients with deviation had surgical closure of a large ventricular septal defect in infancy and a further two patients died before surgery. In two patients with anterior deviation of the outlet septum, the ventricular septal defect was partially closed by fibrous tissue. Surgery for subaortic stenosis was performed more frequently $(P<0.05)$ in patients with posterior deviation $(n=12)$ than in those with anterior deviation $(n=4)$.

Sixteen of the 32 patients (50\%) with short segment obstruction underwent 17 operations for subaortic stenosis. The median (range) age at operation was $5.8(0.3$ to 15.7$)$ years. In six patients subaortic resection was carried out through the ventricular septal defect at the time of surgical closure. In eight patients with small ventricular septal defects, subaortic stenosis was resected through the aortic valve. Two patients, who also had small ventricular septal defects, required aortic valve replacement for valve and subvalve stenosis. Only one patient had already had closure of a large ventricular septal defect.

Figure 8 shows the actuarial freedom from operation for subaortic stenosis in patients with and without deviation. A similar number of patients required surgery for subaortic stenosis in both groups. Those with deviation had resection of subaortic stenosis at a significantly younger age $(P<0.005)$ than those with short segment obstruction. There was no difference in the number of patients with and without deviation who underwent resection of subaortic stenosis at the time of surgical closure of the ventricular septal defect $(P=0 \cdot 16)$

The ventricular septal defect was significantly larger in patients with deviation. In 31 patients with deviation $(93.9 \%)$, the ventricular septal defect required surgical closure because of a large left to right shunt. In only seven patients with short segment obstruction $(21.9 \%)$ was surgical closure indicated $(\mathrm{P}<$ 0.005).

\section{SURVIVAL}

Clinical study

Nine patients $(27 \cdot 3 \%)$ with deviation died This was after surgery in three patients, giving an operative mortality of $18.8 \%$. Six patients died without operation for subaortic stenosis. In three cases this was after surgery for aortic arch obstruction, and in the other three it was after closure of the ventricular septal defect. There were four deaths in patients with short segment obstruction (12\%). This occurred immediately after surgery in two patients, giving an operative mortality of $11 \cdot 8 \%$. Permission was refused for one patient to undergo reoperation for recurrent subaortic stenosis and one patient died after repair of 
Table 5 Current status of the 65 patients in the clinical study with subaortic stenosis and a ventricular septal defect: each patient appears only once

\begin{tabular}{lll}
\hline & $\begin{array}{l}\text { Patients with deviation } \\
\text { of outflow } \\
\text { tract structures } \\
(n=33)\end{array}$ & $\begin{array}{l}\text { Patients with } \\
\text { short segment } \\
\text { obstruction } \\
(n=32)\end{array}$ \\
\hline $\begin{array}{l}\text { Subaortic stenosis } \\
\begin{array}{l}\text { No intervention) } \\
\text { Operation }+\end{array}\end{array}$ & 10 & 15 \\
$\begin{array}{l}\text { survived } \\
\text { Balloon dilatation }+ \\
\text { survived }\end{array}$ & 13 & 13 \\
$\begin{array}{l}\text { Dead } \\
\text { *Three patients died after operation. }\end{array}$ & 0 \\
\hline
\end{tabular}

coarctation. There was no significant difference in mortality in patients with and without deviation $(P=0 \cdot 25)$. There was also no difference in the mortality between patients with the two types of deviation. Table 5 shows the current state of patients.

\section{Discussion}

A ventricular septal defect occurs in $6 \%$ to $25 \%$ of patients with subaortic stenosis, ${ }^{5616}$ and the incidence was slightly higher in this study. The presence or absence of deviation of outflow tract structures in relation to the ventricular septal defect is not usually mentioned. ${ }^{151617}$ In our study $51 \%$ of patients with subaortic stenosis and a ventricular septal defect had deviation. This is similar to one other study in which the presence or absence of deviation was specified. ${ }^{10} \mathrm{We}$ found a similar number of patients and specimens with posterior and anterior deviation. This is comparable with the findings of Smallhorn et al. ${ }^{11}$ In contrast, Zielinsky et al found relatively more patients with anterior deviation. ${ }^{3}$ The reason for this difference is unclear.

We chose the term "deviation" to describe the morphology of the margins of the defect in preference to "malalignment" that is more generally used. "Deviation" allows a more precise description of the structures involved and is less contentious.

\section{MORPHOLOGICAL STUDY}

As far as we know, there have been no reports describing all the structures involved in both types of deviation. Anderson et al described the morphology of four specimens with posterior deviation of the outlet septum and coarctation with a ventricular septal defect. ${ }^{18}$ They also described some specimens with aortic override that was thought to compromise blood flow in the foetal aorta and contribute to the production of coarctation. Structures that contribute to decreased aortic blood flow in the foetus may also cause considerable subaortic stenosis in the infant.

In our study, examination of the pathological specimens provided valuable information about the morphology of the structures involved in the deviation. It showed that obstruction above the defect is not always caused by posterior deviation or hypertrophy of the outlet septum, ${ }^{311}$ as extension of the right ventriculoinfundibular fold may be involved in some cases. The first reports of this condition mentioned a biventricular origin of the pulmonary trunk. ${ }^{12}$ This was subsequently found to be the less common type of morphology, ${ }^{19}$ as we confirmed in our study. In our specimens of this type the outlet septum was either absent when the pulmonary and aortic valves were in fibrous continuity and the obstruction was produced by extension of the right ventriculoinfundibular fold, or as in one case, it was present but hypoplastic. From the left side, this specimen looked similar to others with posterior deviation, but from the right side, override of the pulmonary trunk was clearly visible. In specimens with anterior deviation, aortic override was associated with anterior displacement of the outlet septum into the right ventricle, resulting in obstruction in the left ventricular outflow tract below the ventricular septal defect, as already noted. ${ }^{311}$

\section{CLINICAL STUDY}

The age at presentation was significantly lower in patients with deviation than in those with short segment obstruction. This seemed to be because ventricular septal defects were larger in these patients and they had more symptoms at an earlier age. This difference in the size of the ventricular septal defect was also indicated by the significantly higher incidence of surgical closure of the ventricular septal defect in patients with deviation than in those with short segment obstruction.

A similar number of patients with and without deviation underwent resection of subaortic stenosis, but the age at which this was performed was significantly younger in those with deviation. The site of obstruction also varied. In patients with deviation, a similar number had obstruction above or below the ventricular septal defect whereas, in those with short segment subaortic stenosis, obstruction occurred more commonly below the ventricular septal defect. ${ }^{20}$ There was no significant difference in the recurrence rates for subaortic stenosis as only three patients required reoperation. As far as we know, there are no other surgical reports defining the type of deviation of structures into the left ventricular outflow tract in patients undergoing operation for subaortic stenosis. This study indicated that patients with posterior deviation were more likely to require surgery for subaortic stenosis than those with anterior deviation.

Cross sectional echocardiography before operation seems to be useful in determining which patients with deviation are most likely to develop pronounced subaortic stenosis after surgical closure of the ventricular septal defect. ${ }^{21}$ The type of deviation, which is also clearly seen on cross sectional echocardiography, is of value in predicting the level of obstruction. This information provides the surgeon with the opportunity of dealing with potential obstruction at the time of closure of the ventricular septal defect.

If subaortic stenosis develops after closure of the ventricular septal defect, the transaortic 
approach should result in adequate relief of the obstruction in patients with posterior deviation as the obstruction is above the ventricular septal defect and close to the aortic valve. In those with anterior deviation, obstruction occurs below the ventricular septal defect and lower in the ventricle. This type of anatomy was a less common cause of subaortic stenosis requiring resection in our study, but if obstruction occurs it is more difficult to resect through the aortic valve (fig 2(A)). An approach through the ventricular septal defect such as a modified Konno type procedure may be more appropriate. ${ }^{22}$ This was used in one patient in our study with success. DeLeon et al reported a modified Konno type operation undertaken in three patients with a ventricular septal defect. ${ }^{23}$ The description suggested that these patients had obstruction below the ventricular septal defect due to anterior deviation.

Deviation of the outlet septum does not automatically produce obstruction to one or other outlet. ${ }^{24}$ Examination of the specimens showed that in $18 \%$ of hearts with deviation, the aortic valve circumference was smaller than normal. The aortic diameter at the valve as measured on an angiogram, and the aortic valve circumference measured at necropsy were also consistently smaller than the corresponding measurement of the pulmonary trunk, but the left to right shunt across the ventricular septal defect may explain the increased size of the pulmonary trunk. This aortic to pulmonary ratio is the opposite of that found in tetralogy of Fallot, where the aorta is larger than the pulmonary trunk, and this may explain why subaortic stenosis is rare after repair in this condition. It therefore seems that, in the presence of deviation, the aorta must be large to prevent obstruction.

In both types of deviation there may be impaired growth of the aortic root, which increases the left ventricular outflow obstruction. ${ }^{25} 26$ The aortic valve was also stenotic in about $30 \%$ of patients and specimens in our study, and this contributed to the obstruction in some cases. The development of a fibrous shelf may also contribute towards subaortic stenosis in patients with deviation. Zielinsky et al posed the question whether subaortic fibrosis was congenital or acquired. ${ }^{3}$ Our study of the necropsy specimens showed that fibrous lesions were not present in the first few months of life in patients who died from aortic arch obstruction. The earliest age at which fibrous tissue was seen was at 9 months. Fibrous accretions were seen in $39 \%$ of patients with deviation, confirming that fibrous obstruction develops with time. ${ }^{27}$ This may be as a consequence of a disturbed flow pattern rather than as a result of a congenital abnormality. ${ }^{28}$

\section{ASSOCIATED CARDIAC LESIONS}

Aortic arch obstruction (coarctation or interruption of the aortic arch) was significantly more common in patients with deviation. Some patients with short segment obstruction did have coarctation, but none had an inter- rupted aortic arch. Also, $24 \%$ of patients with deviation had a normal aortic arch. In patients with aortic arch obstruction and subaortic stenosis, posterior deviation has been noted to be the most common association..$^{192526}$ In our study no difference was found in the incidence or type of aortic arch obstruction in the two types of deviation.

About $30 \%$ of patients with aortic arch interruption develop subaortic stenosis. ${ }^{2629} \mathrm{As}$ more infants survive aortic arch reconstruction, with or without simultaneous closure of the ventricular septal defect, ${ }^{29}$ there will be an increasing number of patients with the potential to develop subaortic stenosis. This may best be dealt with at the time of closure of the ventricular septal defect, particularly in those patients with posterior deviation where significant obstruction is likely to occur early in life.

MJ is supported by a grant from the Cardiac Fund, Royal Liverpool Children's NHS Trust. AS is supported by the Endowment Fund of the Royal Liverpool Children's Hospital. We acknowledge the contribution of $\mathrm{Dr} O \mathrm{O}$ Alvarado in formulating some of the concepts included in this work and formulating some of the concepts included in this work
Professor RH Anderson for discussing the work with us.

1 Becu LM, Tauxe WN, DuShane JW, Edwards JE. A complex of congenital cardiac anomalies: ventricular septal defect, biventricular origin of the pulmonary truck, and subaortic stenosis. Am Heart f 1955;50:901-11

2 Neufeld HN, Ongley PA, Swan HJC, Burgert EO, Edwards JE. Biventricular origin of the pulmonary trunk with subaortic stenosis shown above the ventricular septal defect. Am Heart f 1961;61:189-98.

3 Zielinsky P, Rossi M, Haertel JC, Vitola D, Lucchese FA, Rodrigues R. Subaortic fibrous ridge and ventricular Rodrigues $\mathrm{R}$. Subaortic fibrous ridge and ventricular
septal defect: role of septal malalignment. Circulation 1987;75:1124-9.

4 Choi JY, Sullivan ID. Fixed subaortic stenosis: anatomical spectrum and nature of progression. Br Heart F 1991;65: $280-6$

5 Somerville J, Stone S, Ross D. Fate of patients with fixed subaortic stenosis after surgical removal. Br Heart $\mathcal{f}$ 1980;43:629-47.

6 Vogt J, Dische R, Rupprath G, de Vivie ER, Kotthoff St, Kececioglu D. Fixed subaortic stenosis: an acquired secondary obstruction? A twenty-seven year experience with 168 patients. Thorac Cardiovasc Surg 1989;37: 199-206.

7 Fisher DJ, Snider AR, Silverman NH, Stanger P. Ventricular septal defect with silent discrete subaortic stenosis. Pediatr Cardiol 1982;2:265-9.

8 Chung KJ, Fulton DR, Kreidberg AM, Payne DD, Cleveland RJ. Combined discrete subaortic stenosis and ventricular septal defect in infants and children. $A m \mathcal{F}$ ventricular septal defect in
Cardiol 1984;53:1429-32.

9 Smith LDR, Charalmbopoulos C, Rigby ML, Pallides S, Hunter S, Lincoln C, Shinebourne EA. Discrete subaortic stenosis and ventricular septal defect. Arch Dis Child 1985;60:196-9.

10 Iwahara $M$, Ino $T$, Nishimoto $K$, Park I, Akimoto K, Shimazaki $\mathrm{S}$, et al. Clinical features of aortic arch anomaly with malalignment ventricular septal defect. $A n n$ Thorac Surg 1989;48:693-6.

11 Smallhorn JF, Anderson RH, Macartney FJ Morphological characterisation of ventricular septal defects associated with coarctation of the aorta by cross sectional echocardiography. Br Heart f 1983;49:485-94. 2 Bailey NTJ. Mathematics, statistics and systems for health.

2n Armitage P, Berry G. Statistical methods in medical research
2nd. Oxford: Blackwell, 1987:371-421. Kaplan EL, Meier P. Nonparametric estimation from incomplete observations. American Statistical Association fournal 1958;53:457-81.

15 de la Cruz MV, Anselmi G, Romero A, Monroy G. A qualitative and quantitative study of the ventricle and great vessels of normal children. Am Heart $\mathscr{J}$ 1960;60:675-90.

16 Newfeld EA, Muster AJ, Paul MH, Idriss FS, Riker WL. Discrete subvalvular aortic stenosis in childhood. Study of 51 patients. Am $\mathcal{F}$ Cardiol 1976;38:53-61.

17 Freedom RM, Pelech A, Brand A, Vogel M, Olley PM Smallhorn J, Rowe RD. The progressive nature of subaortic stenosis in congenital heart disease. Int $\mathcal{f}$ Cardiol 1985;8:137-43.

18 Anderson RH, Lenox CC, Zuberbuhler JR. Morphology of ventricular septal defect associated with coarctation of the aorta. Br Heart f 1983;50:176-81. 
19 Freedom RM, Dische MR, Rowe RD. Pathologic anatomy of subaortic stenosis and atresia in the first year of life. Am $\mathcal{f}$ Cardiol 1977;39:1035-44.

20 Vogel M, Freedom RM, Brand A, Trusler GA, Williams WG, Rowe RD. Ventricular septal defect and subaortic stenosis: an analysis of 41 patients. Am $f$ Cardiol 1983;52:1258-63.

21 Minich LL, Snider R, Bove EL, Lupinetti FM Echocardiographic predictors of the need for infundibular wedge resection in infants with aortic arch obstruction ventricular septal defect and subaortic stenosis. Am Cardiol 1992;70:1626-7.

22 Cooley DA, Garrett JR. Septoplasty for left ventricula outflow obstruction-without aortic valve replacement: a new technique. Ann Thorac Surg 1986;42:445-8.

23 DeLeon SY, Ilbawi MN, Arcilla RA, Thilenius OG Quinones JA, Duffy EC, Sulayman RF. Transatrial relie of diffuse subaortic stenosis after ventricular septa defect closure. Ann Thorac Surg 1990;49:429-34.

24 Anderson RH, Becker AE, Robertson WB. The cardiovas- cular system (part A) In: Robertson WB, ed. Systemic pathology. 3rd ed. London: Churchill Livingstone, 1993 : 130.

25 Van Praagh R, Bernhard WF, Rosenthal A, Parisi LF Fyler DC. Interrupted aortic arch: surgical treatment. Am 7 Cardiol 1971;27:200-11.

26 Freedom RM, Bain HH, Esplugas E, Dische R, Rowe RD. Ventricular septal defect in interruption of aortic arch. Ventricular septal defect in interruption of aortic arch.

27 Cassidy SC, Van Hare GF, Silverman NH. The probability of detection of a subaortic ridge in children with ventricular septal defect or coarctation of the aorta. Am $\mathcal{F}$ Cardiol 1990;66:505-8.

28 Gewillig M, Daenen W, Dumoulin M, van der Hauwaer L. Rheologic genesis of discrete subvalvular aortic stenosis: a Doppler echocardiographic study. $\mathcal{f} \mathrm{Am}$ Coll Cardiol 1992;19:818-24.

29 Menahem S, Brawn WJ, Mee RB. Severe subaortic stenosis in interrupted aortic arch in infancy and childhood. $f$ Card Surg 1991;6:373-80.

\section{IMAGES IN CARDIOLOGY}

\section{ECG changes of severe hyperkalaemia}

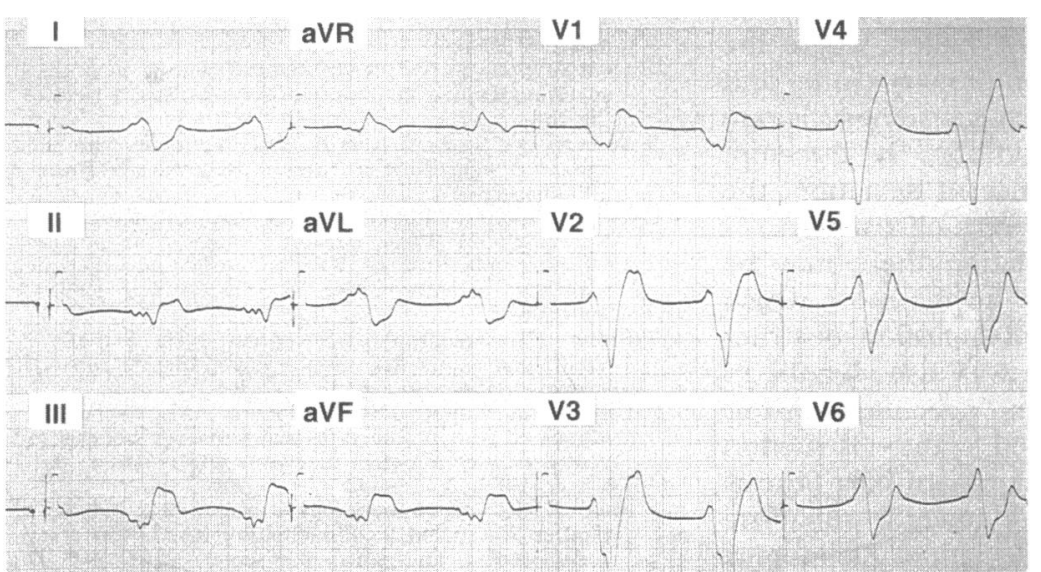

Figure 1 Serum potassium $8.0 \mathrm{mmol} / \mathrm{l}$.

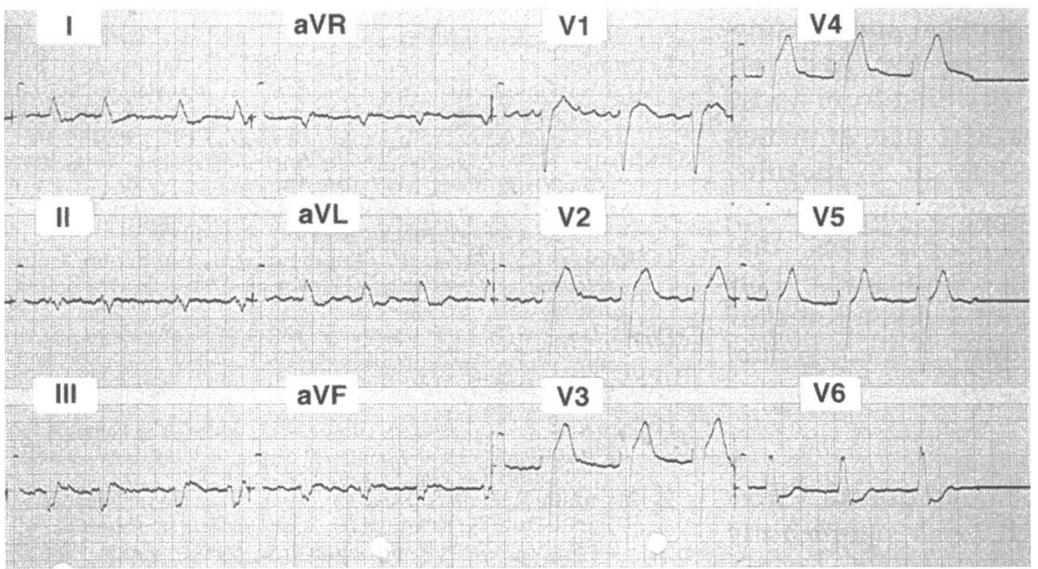

Figure 2 Serum potassium $5 \cdot 3 \mathrm{mmol} / \mathrm{l}$.
A 71 year old man was admitted after being found collapsed at home. Clinically he was in cardiogenic shock with severely impaired cerebration, gross evidence of cardiac failure, a systolic blood pressure of $50 \mathrm{~mm} \mathrm{Hg}$, and a regular pulse of only 42 beats per minute. His initial electrocardiogram is shown (fig 1). As soon as the electrocardiogram was available he was given $10 \mathrm{ml}$ calcium gluconate together with dextrose and insulin. A repeat electrocardiogram performed after these measures was dramatically improved (fig 2). Subsequently, his admission potassium was found to have been greater than 8.0 $\mathrm{mmol} / \mathrm{l}$. It had declined to $5.3 \mathrm{mmol} / \mathrm{l}$ at the time of the second electrocardiogram. Figure 1 shows extremely broad, bizarre QRS complexes with markedly raised ST segments that can be mistaken for the acute injury current of myocardial infarction. In addition there is no evidence of $P$ wave activity. Such electrocardiographic changes may be the harbinger of ventricular tachycardia, fibrillation, or asystole. It is rare to find such gross electrocardiographic changes. More frequently with lesser degrees of hyperkalaemia there are tall, peaked $T$ waves. Increasing hyperkalaemia, however, leads to a progressive reduction in $P$ wave amplitude, $\mathrm{PR}$ prolongation, loss of $\mathrm{R}$ waves, and progressive widening of the $Q R S$ complex.

MALCOLM J METCALFE PETER H SEIDELIN 